The INL is a

U.S. Department of Energy

National Laboratory

operated by

Battelle Energy Alliance

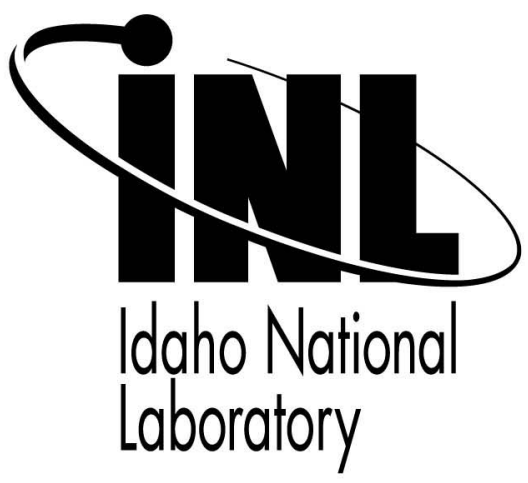

\title{
Strain-Rate Effects on
} Microstructural

Deformation in Irradiated 316 SS

\section{TMS Annual Meeting}

\author{
James I. Cole \\ Hanchung Tsai \\ Todd R. Allen
}

Tsunemitsu Yoshitake

Naoaki Akasaka

Ichiro Yamagata

Yasuo Nakamura

\section{February 2005}

This is a preprint of a paper intended for publication in a journal or proceedings. Since changes may be made before publication, this preprint should not be cited or reproduced without permission of the author. This document was prepared as an account of work sponsored by an agency of the United States Government. Neither the United States Government nor any agency thereof, or any of their employees, makes any warranty, expressed or implied, or assumes any legal liability or responsibility for any third party's use, or the results of such use, of any information, apparatus, product or process disclosed in this report, or represents that its use by such third party would not infringe privately owned rights. The views expressed in this paper are not necessarily those of the United States Government or the sponsoring agency. 


\title{
Strain-rate effects on microstructural deformation in irradiated $316 \mathrm{SS}$
}

\author{
James I. Cole ${ }^{\mathrm{a}, *}$, Hanchung Tsai ${ }^{\mathrm{b}}$, Todd R. Allen ${ }^{\mathrm{c}}$, Tsunemitsu Yoshitake ${ }^{\mathrm{d}}$, \\ Naoaki Akasaka ${ }^{d}$, Ichiro Yamagata ${ }^{\mathrm{d}}$, Yasuo Nakamura ${ }^{\mathrm{d}}$ \\ ${ }^{a}$ Idaho National Laboratory, Nuclear Fuels and Materials Department, P.O. Box I625, MS 6188, Idaho Falls, ID 3783I, USA \\ ${ }^{b}$ Argonne National Laboratory, Argonne, IL, USA \\ ${ }^{\mathrm{c}}$ University of Wisconsin-Madison, Madison, WI, USA \\ d Japan Atomic Energy Research and Development Agency, Oarai-machi, Ibaraki, Japan
}

\begin{abstract}
A series of studies have been performed to investigate the post-irradiation deformation and failure behavior of $12 \%$ cold-worked 316 stainless steel following irradiation to variety of doses and temperatures in the outer rows of the experimental breeder reactor II (EBR-II). In the current phase of these studies, three sets of samples with different radiationinduced microstructures have been characterized with transmission electron microscopy (TEM) following tensile testing to failure at a 'fast' strain-rate $\left(1 \times 10^{-3} \mathrm{~s}^{-1}\right)$ and a 'slow' strain-rate $\left(1 \times 10^{-7} \mathrm{~s}^{-1}\right)$. The samples were irradiated to doses between 9 and $41 \mathrm{dpa}$ at temperatures between 383 and $443{ }^{\circ} \mathrm{C}$. Tensile tests were conducted at a temperature of $430{ }^{\circ} \mathrm{C}$ and only regions outside of the necked region were examined. Over the parameters tested, strain-rate had a negligible effect on the deformation microstructure. In addition, there was no clear evidence of localized deformation behavior and the deformation appeared relatively homogeneous, characterized by unfaulting and incorporation of faulted dislocation loops into the general dislocation network structure. The influence of the defect microstructures and strain-rate on deformation behavior is discussed.
\end{abstract}

\section{Introduction}

Understanding reactor internals degradation resulting from long-term exposure to high levels of displacing radiation damage is vital for aging management of existing commercial reactors and will be an important consideration as advanced reactor

\footnotetext{
* Corresponding author. Tel.: +1 2085337165 ; fax: +1 208533 7863.

E-mail address: Jim.Cole@inl.gov (J.I. Cole).
}

systems are developed that operate at higher temperatures and/or in more aggressive chemical environments than current reactor systems. One of the areas that can be of major concern is how radiation influences the deformation and failure behavior of in-core materials. Studies dating back several decades have shown that highly irradiated metals can be susceptible to plastic instability at relatively low levels of post-irradiation strain leading to the premature onset of necking and failure [1-5]. This type of behavior has been related to heterogeneous microstructural deformation processes caused by 
the interaction of microstructural elements introduced during deformation with the existing radiation-induced microstructure.

The link between these radiation induced changes in microstructure and plastic deformation and failure behavior of austenitic stainless steels has yet to be completely understood. Microstructural deformation behavior has been observed to be strongly influenced by such factors as alloy composition, irradiation temperature, dose, testing temperature and strain-rate [1-9]. In order to qualify alloys for potential application in advanced reactor systems, it will be critical to understand deformation and failure behavior over a range of expected operating conditions.

Several recent studies have shown that at lower irradiation and testing temperatures, deformation in irradiated stainless steel proceeds by the formation of extremely fine twins and/or the generation of defect free dislocation channels along the $\left\{\begin{array}{lll}1 & 1 & 1\end{array}\right\}$ type slip planes. The deformation is characterized by the highly planar motion of dislocations [6-9]. These studies have focused on lower dose and temperature irradiations where the primary microstructural constituents are small black spot-damage, small faulted loops and in some cases, small bubbles. It is still unclear how irradiation and testing parameters influence the deformation behavior of highly irradiated austenitic stainless steels containing populations of voids, large faulted dislocation loops and precipitates.

Following shutdown of EBR-II, a variety of stainless steel internal structural components with well characterized temperature, flux and fluence histories became available for study. Some of these materials resided in regions outside the fueled region of the core in the reflector and blanket regions and thus experienced irradiation conditions different than those previously studied during reactor operation. In the current study, the effect of the radiationinduced microstructure (as a function of dose and irradiation temperature) and strain-rate on the post-irradiation deformation behavior of a $12 \%$ cold-worked 316 SS are evaluated.

\section{Experimental}

The tensile and TEM samples were obtained from one of two separate reflector subassembly hexagonal ducts. The hexagonal ducts were seam welded and approximately $0.1 \mathrm{~cm}$ thick by $3.2 \mathrm{~cm}$ on a side, by $150 \mathrm{~cm}$ long. One duct was irradiated in row 8 of the core while the other was irradiated in row 9. The ducts resided in core for 980 (row 8 duct) and 2088 (row 9 duct) effective full power days prior to removal. The irradiation temperature of the ducts ranged from $370^{\circ} \mathrm{C}$ near the sodium coolant inlet to $440^{\circ} \mathrm{C}$ at the top of the core. Flux gradients in both the axial and radial directions provided samples over a substantial range of doses (1-56 dpa) and dose-rates $\left(1 \times 10^{-8}\right.$ to $\left.6 \times 10^{-7} \mathrm{dpa} / \mathrm{s}\right)$. Fig. 1 provides an illustration of the EBR-II core, including a graph of the displacement rate as a function of distance from the core centerline. The irradiation and test conditions of the samples examined in this study are listed in Table 1.

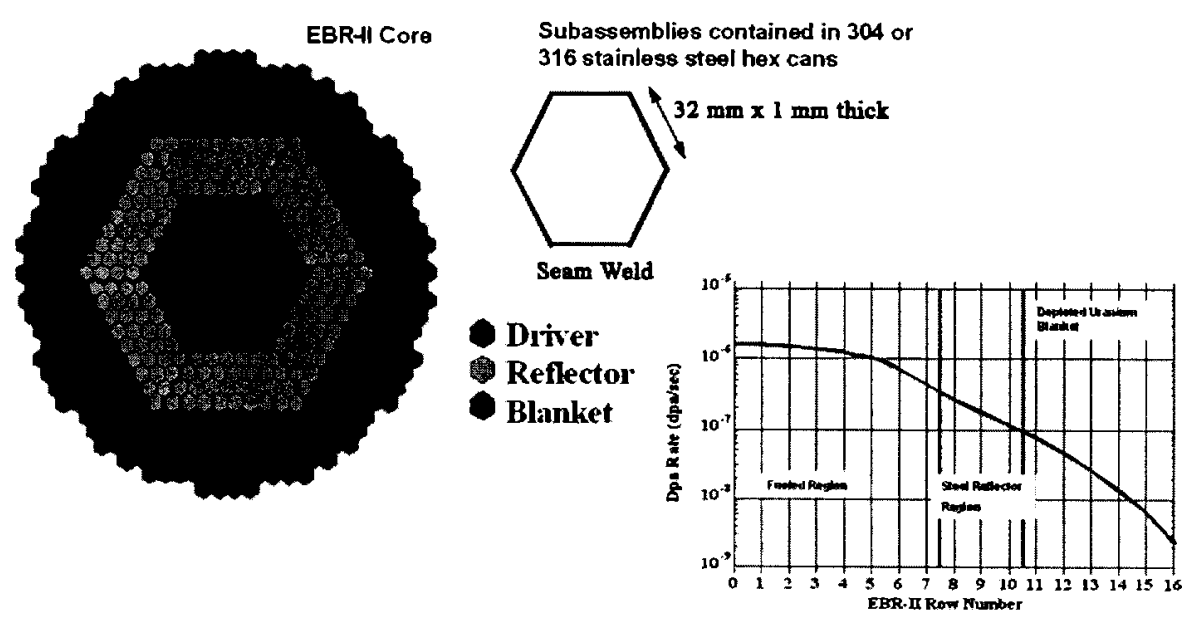

Fig. 1. Schematic representation of EBR-II core and hex duct assembly, including graph of displacement rate as a function of distance from core center. 
Table 1

Irradiation and test conditions for $12 \% \mathrm{CW} 316 \mathrm{SS}$

\begin{tabular}{llllll}
\hline Sample ID & Irradiation temperature $\left({ }^{\circ} \mathrm{C}\right)$ & Dose $(\mathrm{dpa})$ & Dose rate $(\mathrm{dpa} / \mathrm{s})$ & Test temperature $\left({ }^{\circ} \mathrm{C}\right)$ & Strain-rate $\left(\mathrm{s}^{-1}\right)$ \\
\hline U9861 ET16 & 443 & 9.1 & $1.07 \times 10^{-7}$ & & Not deformed \\
U9861 ET05 & 444 & 9.1 & $1.06 \times 10^{-7}$ & 429 & $1 \times 10^{-3}$ \\
U9861 ET12 & 443 & 9.1 & $1.06 \times 10^{-7}$ & 430 & $1 \times 10^{-7}$ \\
U9922 NT17 & 432 & 18.2 & $1.01 \times 10^{-7}$ & & Not deformed \\
U9922 NT12 & 432 & 19.2 & $1.06 \times 10^{-7}$ & 428 & $1 \times 10^{-3}$ \\
U9922 NT06 & 433 & 19.2 & $1.06 \times 10^{-7}$ & 430 & $1 \times 10^{-7}$ \\
U9922 NT14 & 388 & 41.2 & $2.27 \times 10^{-7}$ & & Not deformed \\
U9922 NT08 & 409 & 40.5 & $2.23 \times 10^{-7}$ & 429 & $1 \times 10^{-3}$ \\
U9922 NT03 & 383 & 40.6 & $2.24 \times 10^{-7}$ & 429 & $1 \times 10^{-7}$ \\
\hline
\end{tabular}

To examine irradiated samples before deformation, $2 \mathrm{~cm}$ discs were punched from the flats for density measurements, and $3 \mathrm{~mm}$ TEM discs were subsequently punched from the density discs. For the deformed samples, sheet tensile samples were electric discharge machined from the flats of the hexagonal ducts. The samples were approximately $60 \mathrm{~mm}$ in total length with a gauge width and length of $3 \mathrm{~mm}$ and $19 \mathrm{~mm}$, respectively. The tensile tests were performed on a screw-driven Instron Universal Testing Machine. Tests were carried out at strainrates of $10^{-3}$ and $10^{-7}$ per second. The tests were conducted to sample failure, and in the case of the slower strain-rate, lasted up to several weeks.

Following testing, one half of the gauge section of the failed samples was sectioned from the grip, and the samples were prepared as thin foils for transmission electron microscopy examination. A JEOL 2010 TEM was used to characterize the microstructures. Sample thickness for quantitative measurements was determined using convergent beam electron diffraction.

\section{Results}

Examination of the irradiated samples before deformation showed both large annealing twins and substantial residual deformation twining present from the initial 12\% cold-work (see Fig. 2). Twin density varied significantly from grain-to-grain in the samples, with some grains being completely absent of the twins. The deformation twin density appeared similar prior to deformation and following tensile testing of the samples. However, due to the large variations in twin density and inability to distinguish twins formed prior to and following testing, this observation could not be quantitatively verified. The voids in the twinned regions appear not to

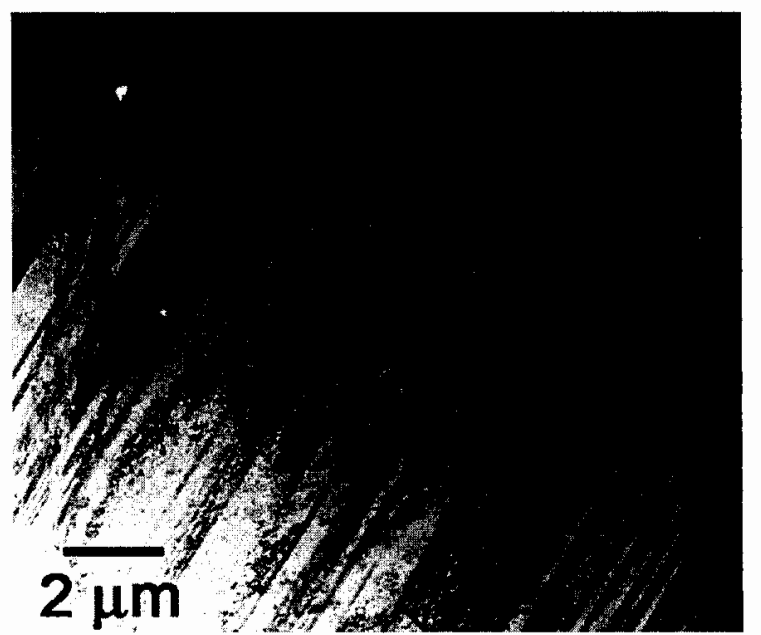

Fig. 2. Image of untested $12 \% \mathrm{CW} 316 \mathrm{SS}$ irradiated to approximately $9 \mathrm{dpa}$. Substantial deformation twins are observed in the microstructure.

have undergone any significant shape change (such as elongating in the direction of twinning) which suggests the twins were present prior to tensile testing.

Values for strength and ductility of the samples examined are tabulated in Table 2. It is important to note that since regions of the tensile samples away from the necked region were examined, the extent of deformation is more closely represented by the uniform elongation of the sample rather than the strain at failure or total elongation. The sample NT03 was irradiated at a temperature approximately $20^{\circ} \mathrm{C}$ below that of NT08, which may account for the lower uniform elongation.

The microstructures of the irradiated samples contained varying densities of voids, precipitates and dislocations (both loop and line/network dislocations) depending on the dose and temperature. 
Table 2

Summary of tensile data for examined samples tested at $430^{\circ} \mathrm{C}$

\begin{tabular}{|c|c|c|c|c|}
\hline $\begin{array}{l}\text { Sample }-\dot{\varepsilon} \\
\text { Dose (dpa), } T_{\text {irr }}\end{array}$ & $\begin{array}{l}\text { Yield } \\
\text { strength (MPa) }\end{array}$ & $\begin{array}{l}\text { Ultimate tensile } \\
\text { strength (MPa) }\end{array}$ & $\begin{array}{l}\text { Uniform } \\
\text { elongation (\%) }\end{array}$ & $\begin{array}{l}\text { Total } \\
\text { elongation }(\%)\end{array}$ \\
\hline $\begin{array}{l}\text { ET05 - } 10^{-3} \mathrm{~s}^{-1} \\
9.1 \mathrm{dpa}, 444^{\circ} \mathrm{C}\end{array}$ & 545 & 667 & 10.4 & 13.9 \\
\hline $\begin{array}{c}\text { ET12-10 } 0^{-7} \mathrm{~s}^{-1} \\
9 \mathrm{dpa}, 443^{\circ} \mathrm{C}\end{array}$ & 575 & 725 & 11.8 & 14.0 \\
\hline $\begin{array}{l}\mathrm{NT} 12-10^{-3} \mathrm{~s}^{-1} \\
19.2 \mathrm{dpa}, 432{ }^{\circ} \mathrm{C}\end{array}$ & 643 & 750 & 8.0 & 10.3 \\
\hline $\begin{array}{l}\text { NT06 }-10^{-7} \mathrm{~s}^{-1} \\
\quad 18.2 \mathrm{dpa}, 432^{\circ} \mathrm{C}\end{array}$ & 630 & 749 & 8.4 & 11.6 \\
\hline $\begin{array}{l}\text { NT08 - } 10^{-3} \mathrm{~s}^{-1} \\
\quad 40.5 \mathrm{dpa}, 409^{\circ} \mathrm{C}\end{array}$ & 709 & 776 & 5.4 & 7.4 \\
\hline $\begin{array}{l}\mathrm{NT} 03-10^{-7} \mathrm{~s}^{-1} \\
41.2 \mathrm{dpa}, 388^{\circ} \mathrm{C}\end{array}$ & 740 & 820 & 1.6 & 3.8 \\
\hline
\end{tabular}

Images of the void microstructures in the samples are shown in Fig. 3. Also indicated on the images of the undeformed samples is the measured average void size, density and calculated swelling. The average void size and density are also indicated for the tested samples irradiated to the highest dose. The void densities are much greater, and the void sizes typically smaller in the high dose samples irradiated at the lowest temperature. Because of the low number densities of voids in the 9 and 19 dpa samples, the swelling in these two conditions was quite low. Even in the highest dose sample, swelling due to void formation is calculated to be less than $1 \%$. Two items should be noted: (1) there is an approximately $20^{\circ} \mathrm{C}$ difference in irradiation temperature between the untested and $10^{-7} \mathrm{~s}^{-1}$ samples and the $10^{-3} \mathrm{~s}^{-1}$ sample, which is likely the cause of the larger void size and lower density in this sample; (2) because the highest dose samples were irradiated at lower temperatures than the testing temperature, there is the potential for annealing of the microstructure during the tests. However, in comparison to the untested sample, no discernable evidence of such annealing can be found.

The dislocation microstructure images are shown in Fig. 4. The images were taken under weak beam dark-field imaging conditions using a large deviation from the Bragg condition. In the case of the undeformed samples, (top row) there is a high density of faulted dislocation loops at all three irradiation conditions. The loop size increases with irradiation temperature, and the density appears to saturate with increasing dose. In the tested sam- ples, the faulted loop density is decreased dramatically, being nearly eliminated in the lower dose samples. The loops appear to have unfaulted and been incorporated into the dislocation structure. Features that appear to be extended stacking faults were also observed though their density was quite low. No denuding of dislocations or voids was observed to occur near grain boundary in any of the samples.

\section{Discussion}

A variety of studies have been conducted on the microstructural deformation behavior of austenitic stainless irradiated at lower temperatures $\left(<300^{\circ} \mathrm{C}\right)$ and tested over a range of temperatures [6-11]. The microstructures produced by lower temperature irradiation are substantially different than those observed in the current study and on comparison to these studies, can serve to indicate controlling mechanisms in changing deformation behavior. The lower temperature irradiations tend to produce high densities of fine $(<10 \mathrm{~nm})$ defects such as black spot damage, small faulted loops and small helium bubbles. Substantial second phase precipitation is typically not observed at these lower temperatures. In comparison, the microstructures produced in samples irradiated in the EBR-II between approximately 380 and $445^{\circ} \mathrm{C}$ are composed of large $(>20 \mathrm{~nm})$ faulted loops, voids and significant second phase precipitation.

Examples of behavior that occurs at lower irradiation and test temperatures include changes in 


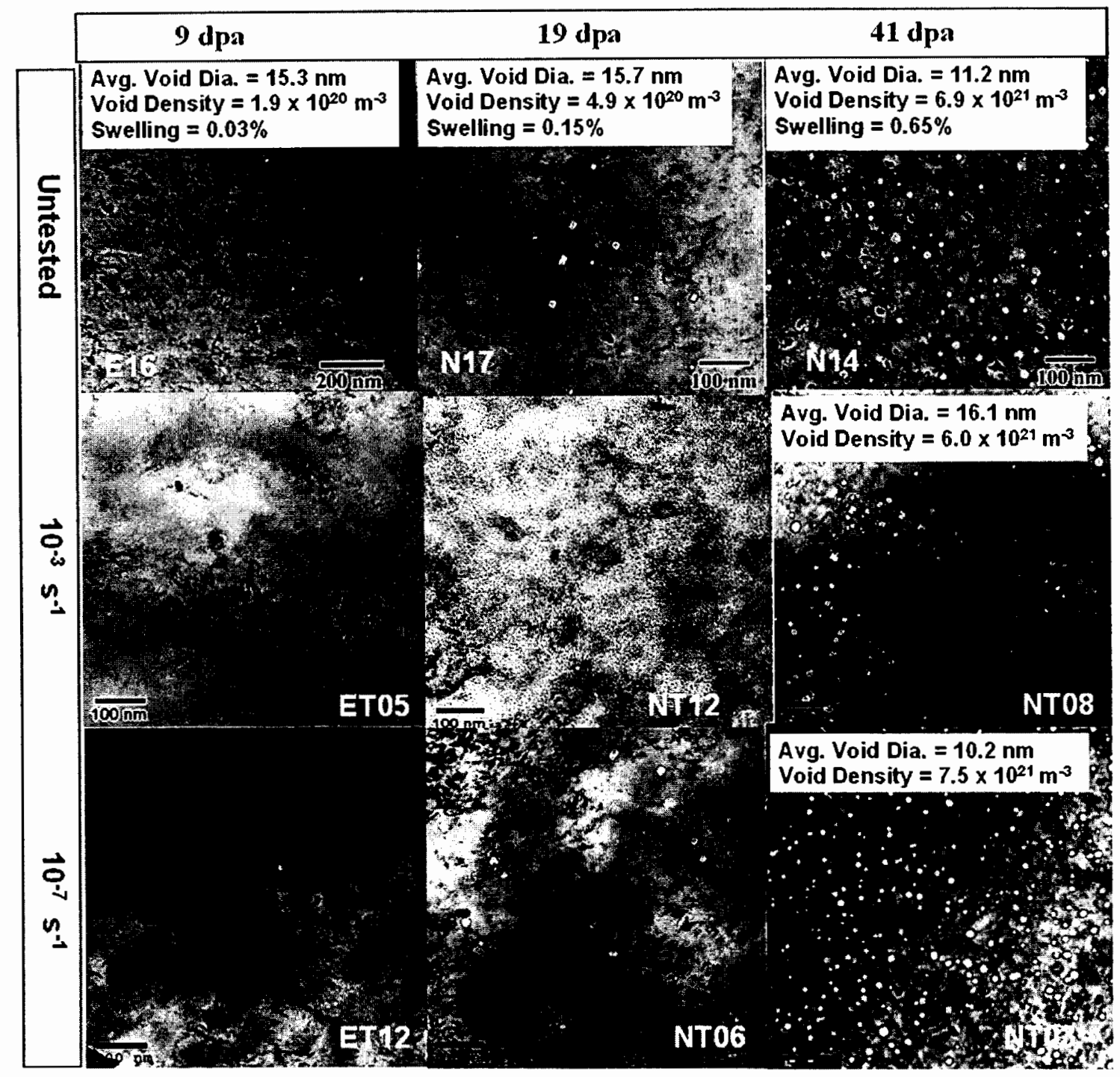

Fig. 3. Void microstructures in $12 \% \mathrm{CW} 316 \mathrm{SS}$ irradiated in EBR-II.

deformation mode with increasing test temperature and decreasing strain-rate as observed in samples of heavy-ion irradiated 304 SS tested at room temperature and $288^{\circ} \mathrm{C}[6,7]$. The samples were irradiated at $500^{\circ} \mathrm{C}$, but because of the temperature shift due to the increased displacement rate of heavy-ions, the microstructures formed are similar to those formed in $300^{\circ} \mathrm{C}$ neutron irradiations. Microstructural deformation behavior transitioned from dislocation glide to deformation twinning with increasing dose at room temperature, while at $288^{\circ} \mathrm{C}$ both twinning and dislocation channeling were observed at a strain-rate of $2.0 \times 10^{-4} \mathrm{~s}^{-1}$.
With the strain-rate decreasing to $2.5 \times 10^{-6} \mathrm{~s}^{-1}$, the deformation mode switched completely to dislocation channeling. These results are in contrast to the current study, which suggests there is no strong influence of strain-rate on microstructural deformation behavior for the irradiation and testing conditions examined.

In $316 \mathrm{LN}$ samples irradiated at $200{ }^{\circ} \mathrm{C}$ with $\mathrm{He}$ ions, and deformed in a disc bend fixture to approximately $10 \%$ strain $[8,9]$, high densities of extended faults are generated with the deformation becoming more planar with increasing dose. Extended faults were observed to cluster into bands forming twins, 


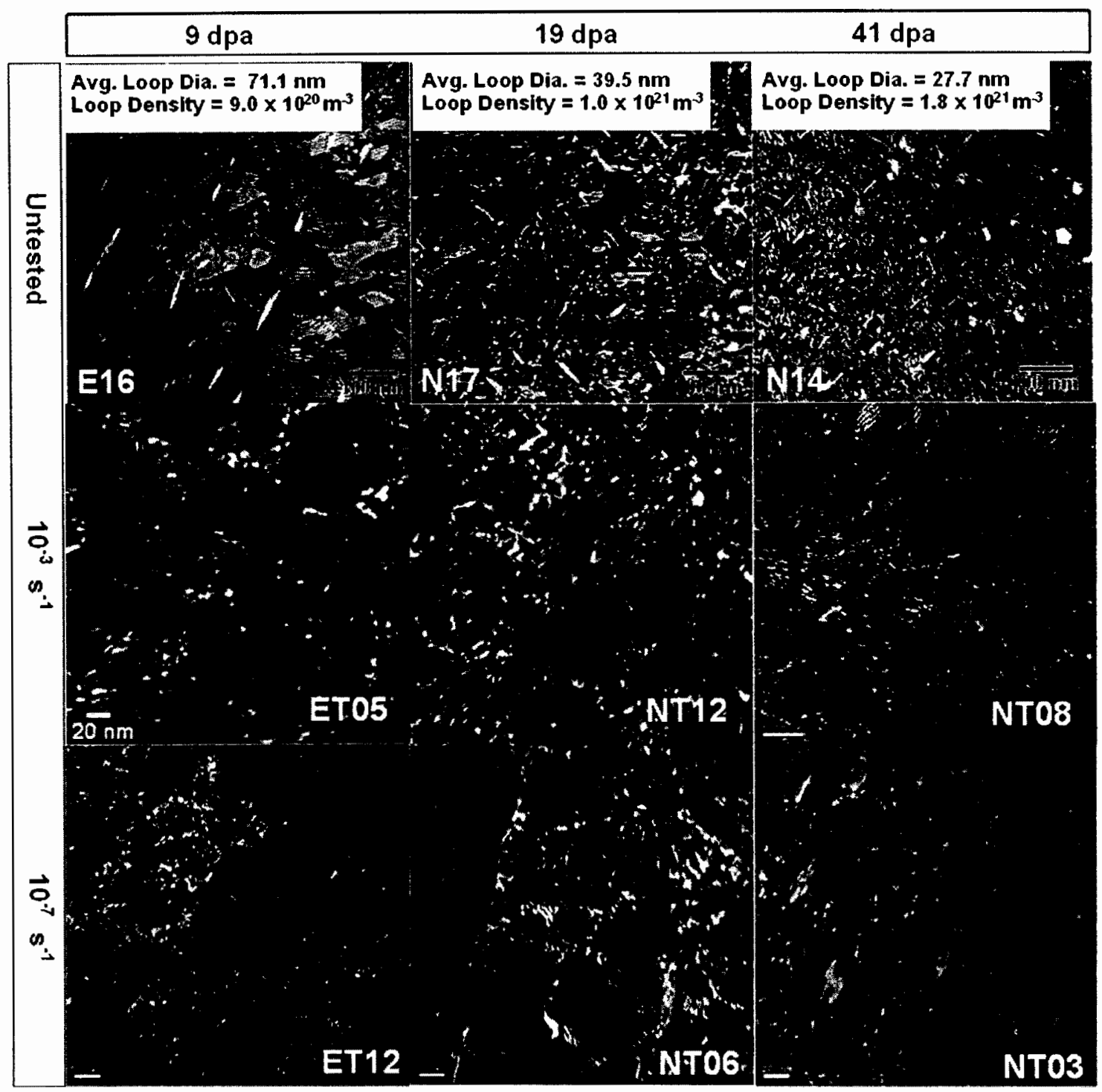

Fig. 4. Dislocation microstructures in $12 \% \mathrm{CW} 316$ SS irradiated in EBR-II.

and it is conjectured that the passage of the leading dislocation of the extended stacking fault results in unfaulting and clearing of the defects forming reduced defect channels. The impact of the radiation-induced defects is to restrict cross-slip and induce highly planar deformation behavior. If such a mechanism were present in the current samples, the twins observed in the microstructure would contain reduced populations of defects. Observations indicated that this is not the case and it seems that neither twin nor channel formation are present.

One other interesting study showed that twenty percent CW 316 SS samples which were irradiated to high dose $\left(13-17 \times 10^{22} \mathrm{n} / \mathrm{cm}^{2}(E>0.1 \mathrm{MeV})\right)$ and tensile tested over a range of temperatures revealed the formation of high densities of fine martensite platelets [12]. It was conjectured that the large amount of swelling in the alloys led to depletion of $\mathrm{Ni}$ in the surrounding matrix causing the material to become unstable against the formation of martensite. The fracture surface at lower temperatures was perpendicular to the tensile axis, indicating brittle cleavage failure, while at higher temperatures failure was characterized by flow localization, a process termed channel fracture. TEM images revealed the regions of extreme localization contained voids 
elongated in the direction of the shear. Although the alloy in the earlier study was similar to that irradiated in this study, the samples were irradiated to higher doses, consequently to which the amount of swelling was also greater. Comparison between this earlier study and the present results would suggest that there is a critical dose, related primarily to the extent of swelling, at which radiation-induced matrix compositional changes can lead to changes in deformation behavior.

The TEM results are consistent with observed tensile behavior. In addition to the three samples examined in this study an additional six samples were tested to compare strain-rate effects [13]. There was no statistically measurable difference in the UTS and UE of these samples as a function of strain-rate. The only major difference was all samples tested at lower strain-rate exhibited dynamic strain aging behavior which manifests itself as serrations in the stress-strain curve. This behavior is also commonly seen in unirradiated samples tested at slow strain-rates and is caused by the pinning of dislocations by solute atoms [14]. When stress level is high enough, the dislocations break free of their solute environment, causing a load drop. Once the dislocations have come to rest, solute atom diffusion pins them once again, leading to load oscillations with increasing strain.

In combination, the current and earlier works suggest there is a relatively complex relationship between alloy deformation behavior and irradiation and testing conditions. Irradiation conditions that produce high densities of small (10 nm or less) obstacles tend to enhance a transition to localized planar deformation at lower testing temperatures, and decreasing strain-rate. On the contrary, such behavior is not observed in samples irradiated and tested at the elevated temperatures investigated in the present study. One possible explanation for this change in behavior with temperature is the combination of larger faulted dislocation loops and increasing stacking fault energy with temperature. Larger loops are less stable and more likely to unfault particularly at elevated temperatures. Additionally, because stacking fault energy increases with temperature [14], the restrictions on cross-slip are eased and the highly planar deformation behavior that leads to dislocation channeling and the early onset of plastic instability is absent. As mentioned previously, it can not be stated conclusively that localization of the deformation will not occur at higher levels of strain. In order to evaluate this, the necked region of the tensile gauge would have to be analyzed.

\section{Conclusions}

The transition to highly localized deformation behavior and early onset of plastic instability observed in studies conducted at lower irradiation and testing temperatures is not present in $12 \%$ CW 316 SS irradiated in the temperature and dose ranges of $380-440^{\circ} \mathrm{C}$ and $9-42 \mathrm{dpa}$, respectively and tested at $430^{\circ} \mathrm{C}$. Deformation behavior was not observably changed as a function of strain-rate, and appeared to proceed by the unfaulting of dislocation loops and the relatively uniform gliding of dislocations. Such behavior can be explained by the relatively unstable nature of faulted dislocation loops at these temperatures, and the enhanced ability for dislocations to cross-slip.

\section{Acknowledgements}

The authors wish to thank D. McGann, T.A. Burtseva, D. Pushis, L.F. Essenmacher, and N. Hins, Argonne National Laboratory, for specimen preparation and testing. They also wish to thank K.N. Grimm, Argonne National Laboratory, for the EBR-II radial reflector DPA calculations. Work was supported by US Department of Energy under contract no. W-31-109-ENG-38 with the Japan Nuclear Cycle Development Institute.

\section{References}

[1] B. Mastel, H.E. Kissinger, J.L. Laidler, T.K. Bierlein, J. Appl. Phys. 34 (1963) 3637.

[2] M.S. Weschler, in: R.E. Reed-Hill (Ed.), The inhomogeneity of plastic deformation, ASM, 1973, p. 19.

[3] T. Onchi, H. Kayano, Y. Higashiguchi, J. Nucl. Mater. 88 (1980) 226.

[4] T.S. Byun, K. Farrell, Acta Mater. 52 (2004) 1597.

[5] J.V. Sharp, Philos. Mag. 16 (1967) 77.

[6] J.I. Cole, S.M. Bruemmer, J. Nucl. Mater. 225 (1995) 53.

[7] J.I. Cole, J.L. Brimhall, J.S. Vetrano, S.M. Bruemmer, in: Proceedings of the Seventh International Symposium on Environmental Degradation of Materials in Nuclear Power Systems-Water Reactors, NACE, 1995, p. 817.

[8] E.H. Lee, T.S. Byun, J.D. Hunn, K. Farrell, L.K. Mansur, J. Nucl. Mater. 296 (2001) 183.

[9] T.S. Byun, E.H. L.ee, J.D. Hunn, J. Nucl. Mater. 321 (2003) 29.

[10] S.M. Bruemmer, J.I. Cole, R.D. Carter, G.S. Was, Defect microstructures and deformation mechanisms in irradiated austenitic stainless steels, in: MRS Symposium Proceedings: 
Microstructure Evolution During Irradiation, Materials Research Society, 1987, p. 437.

[11] T.S. Byun, N. Hashimoto, K. Farrell, Acta Mat. 52 (2004) 3889.

[12] M.L. Hamilton, F. Huang, W.J.S. Yang, F.A. Garner, in: F.A. Garner, C.H. HenagerJr. (Eds.), Proceedings of Influ- ence of Radiation in Material Properties: Symposium (Part II), ASTM STP, 956, American Society for Testing and Materials, Philadelphia, 1987, p. 245.

[13] T. Yoshitake, I. Yamagata, N. Akasaka, Y. Nakamura, H. Tsai, J.I. Cole, T.R. Allen, J. ASTM Int. 3 (2006).

[14] J.M. Robinson, M.P. Shaw, Int. Met. Rev. 39 (1994) 113. 